\title{
Nanocrystalline Ni-Co Alloy Synthesis by High Speed Electrodeposition
}

\author{
Jamaliah Idris, Chukwuekezie Christian, and Eyu Gaius \\ Faculty of Mechanical Engineering, Universiti Teknologi Malaysia, 81310 Skudai, Johor Bahru, Malaysia \\ Correspondence should be addressed to Jamaliah Idris; jamaliah@mail.fkm.utm.my
}

Received 9 April 2013; Revised 19 May 2013; Accepted 21 May 2013

Academic Editor: Fathallah Karimzadeh

Copyright (c) 2013 Jamaliah Idris et al. This is an open access article distributed under the Creative Commons Attribution License, which permits unrestricted use, distribution, and reproduction in any medium, provided the original work is properly cited.

\begin{abstract}
Electrodeposition of nanocrystals is economically and technologically viable production path for the synthesis of pure metals and alloys both in coatings and bulk form. The study presents nanocrystalline Ni-Co alloy synthesis by high speed electrodeposition. Nanocrystalline Ni-Co alloys coatings were prepared by direct current (DC) and deposited directly on steel and aluminum substrates without any pretreatment, using high speed electrodeposition method. The influence of the electrolysis parameters, such as cathodic current density and temperature at constant $\mathrm{pH}$, on electrodeposition and microstructure of Ni-Co alloys were examined. A homogeneous surface morphology was obtained at all current densities of the plated samples, and it was evident that the current density and temperature affect the coating thickness of Ni-Co alloy coatings.
\end{abstract}

\section{Introduction}

Nanocrystalline Ni-Co alloy synthesis has gained tremendous attention of researchers in recent time. Many approaches have been used for its production, which include ball milling, gas condensation, sol-gel techniques, and particularly electrodeposition approach. However, electrodeposition technique has advantages over others. In elecrodeposition, grain size less than $100 \mathrm{~nm}$ of pure metal, alloys, and composite can be deposited on a large scale. Additionally, it is relatively less expensive [1]. Moreover, production rate is high with minimal size and shape limitations. Another excellent characteristic of electrodeposition includes the ability to be applied to a variety of substrate materials [2]. Electrodeposition is an electrochemical liquid phase thin film or powder preparation method where the reactions, either reduction or oxidation, are accomplished using an external current source. It is a low temperature processing route to produce nanostructured materials, most often in a single step requiring no secondary consolidation.

Certain electrodeposition variables such as current density, temperature, particle concentration, $\mathrm{pH}$ value, and bath composition are of great importance during synthesis of $\mathrm{Ni}$ Co alloy [3-6]. Similarly, high speed jet electrodeposition addresses the issue of drawbacks posed by convectional electroplating in the dispersion of particles in electrolytic bath because of its special flow characteristic [7]. With these aforementioned benefits identified, Ni-Co coatings by electrodeposition have wide range of applications such as in automotive parts, aerospace, rocket technology, cosmonautics, sound signals, medical applications, nuclear power systems, and magnetic devices, as anticorrosive coatings [8], as well as decorative purposes [9].

Synthesis of nanocrystalline coatings from metal and its alloys, with grain size less than $100 \mathrm{~nm}$, using electrodeposition method has been reported. However, the use of conventional electrodeposition techniques during synthesis of materials has been limited in its wide range practical applications because of its low deposition rate, which results in less nucleation of grains on the substrates. This affects the surface morphology, microstructure, and the coating orientation. To overcome this concern, high speed jet electrodeposition was used in synthesis of nanocrystalline $\mathrm{Ni}-\mathrm{Co}$ alloy, which will produce massive grain nucleation on the substrate because of enhanced flow rate characteristics. 
TABLE 1: The composition of electroplating bath.

\begin{tabular}{lcccc}
\hline Bath & Composition & Concentration $(\mathrm{g} / \mathrm{L})$ & Temperature $\left({ }^{\circ} \mathrm{C}\right)$ & Current density $\left(\mathrm{A} / \mathrm{dm}{ }^{2}\right)$ \\
\hline \multirow{3}{*}{ Watt's } & $\mathrm{CoSO}_{4} \cdot 7 \mathrm{H}_{2} \mathrm{O}$ & 480 & & \\
& $\mathrm{H}_{3} \mathrm{BO}_{3}$ & 240 & $55-65$ & $0.1-1.0$ \\
& $\mathrm{NiCl}_{2} \cdot 6 \mathrm{H}_{2} \mathrm{O}$ & 1500 & & \\
\hline
\end{tabular}

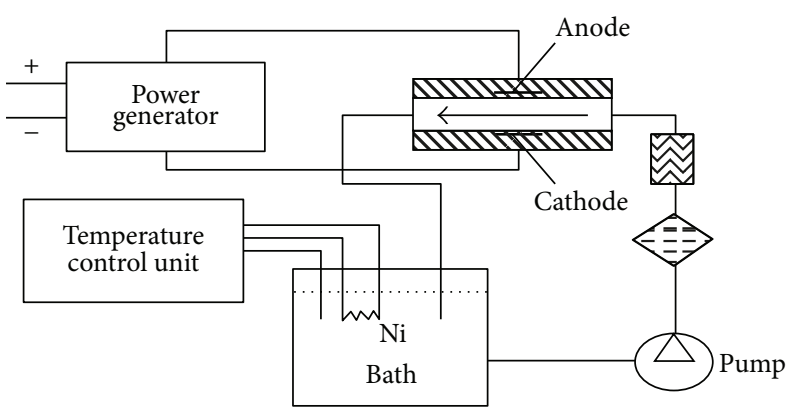

FIGURE 1: Schematic illustration of the high speed plating equipment.

TABLE 2: The summary of substrate samples preparation according to the composition of solution, current density, and temperature.

\begin{tabular}{lccc}
\hline $\begin{array}{l}\text { Samples }(\mathrm{A} \text { and } \mathrm{B}) \\
\text { No. }\end{array}$ & $\begin{array}{c}\text { Solution } \\
\text { composition }\end{array}$ & $\begin{array}{c}\text { Temperature } \\
\left({ }^{\circ} \mathrm{C}\right)\end{array}$ & $\begin{array}{c}\text { Current density } \\
\left(\mathrm{A} / \mathrm{cm}^{-2}\right)\end{array}$ \\
\hline 1 & & 55 & 0.1 \\
2 & & & 0.3 \\
3 & & & 0.5 \\
4 & $\mathrm{CoSO}_{4} \cdot 7 \mathrm{H}_{2} \mathrm{O}$ & & 0.1 \\
5 & $\mathrm{NiCl}_{2} \cdot 6 \mathrm{H}_{2} \mathrm{O}$ & 60 & 0.3 \\
6 & $\mathrm{H}_{3} \mathrm{BO}_{3}$ & & 0.5 \\
7 & & & 0.1 \\
8 & & 65 & 0.3 \\
9 & & & 0.5 \\
\hline
\end{tabular}

\section{Experimental Methods}

2.1. Materials. Mild steel and aluminium were used as substrates, as well as Ni-Co alloy for electroplating. Table 1 shows the chemical composition and concentration of the electroplating bath used for the experiment.

\subsection{Methods}

2.2.1. Sample Preparation. Commercial mild steel and aluminum of $10 \times 60 \mathrm{~mm}$ without any preplating were used. The anode for the deposition of Ni-Co alloy was pure nickel sheet. The specimens were mechanically polished using abrasive paper of various grades to a good surface finish, then cleaned only with distilled water, and allowed to dry in an open air before plating prior to deposition. The summary of substrate samples preparation according to the composition of solution, current density, and temperature is shown in Table 2.
2.2.2. Experiment Setup. Figure 1 shows schematically the experimental setup of high speed electroplating apparatus. The volume of the electrolyte was $8 \mathrm{dm}^{3}$ of Watt's nickel solution. The substrates (mild steel and aluminum) were placed at electrodes of high speed plating equipment. The space between the anode and cathode during plating is $10 \mathrm{~mm}$. The substrates were put at the cathode consecutively and $99.9 \%$ nickel was the anode. Watt's nickel solution was put inside the solution bath, and the temperature of the electrolyte was controlled by using temperature control component. The pump was turned on, and immediately the solution flows rapidly from the tank into the pipe through the two compartments (anode and cathode) and then flows into the tank in a reversed direction to make a complete cycle. The power generator (rectifier) was turned on and current density adjusted to the desired rate. The electrodeposition process is carried out at fixed speed of $2.7 \mathrm{~m} / \mathrm{s}$ and set time of 3 minutes for all the samples.

After the deposition, surface morphology, chemical composition, microstructure, and the thickness of the coating were characterized with optical microscopy and SEM with EDX.

2.3. Materials Characterization. The effects of varying experimental conditions and chemical compositions of the coatings on their microstructure were characterized using optical microscopy and SEM with EDX.

2.3.1. Optical Microscopy. The Nikon Microphot FX optical microscope was used to provide basic information about the microstructure of the samples and measurement of the coating thickness. The grinding was performed using silicon carbide water proof paper, with grit sizes of 220, 320, 400, 600, 800,1000 , and 1200 . After thorough grinding, the sample was polished in a rotary machine. Thereafter, the sample was dried and subjected to etching using ethanol and nitric acid before the microstructure was viewed using the Nikon microscope. 


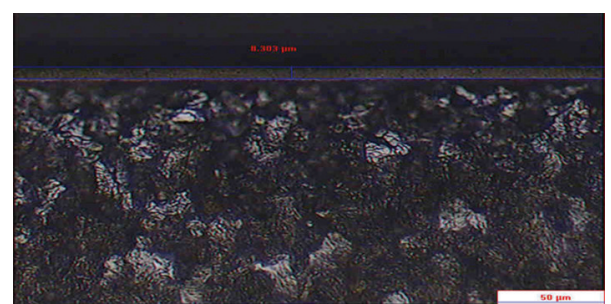

(a)

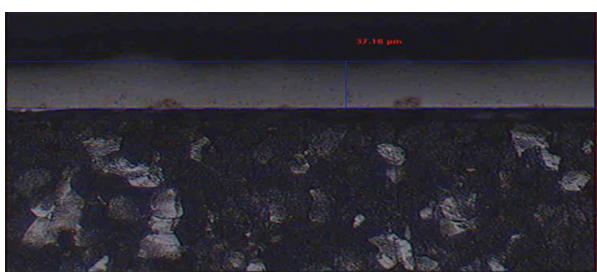

(c)

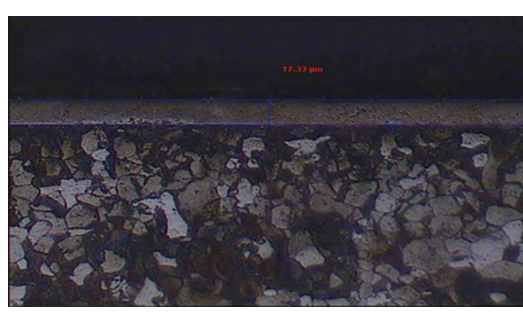

(b)

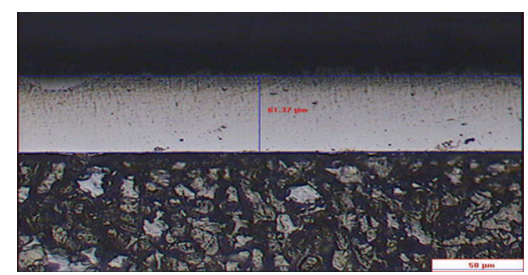

(d)

Figure 2: Micrograph of Ni-Co plated on mild steel surface at $55^{\circ} \mathrm{C}$ for (a) $0.1 \mathrm{~A} / \mathrm{cm}^{2}$, (b) $0.3 \mathrm{~A} / \mathrm{cm}^{2}$, (c) $0.5 \mathrm{~A} / \mathrm{cm}^{2}$, and (d) $1 \mathrm{~A} / \mathrm{cm}^{2} \mathrm{current}$ densities.

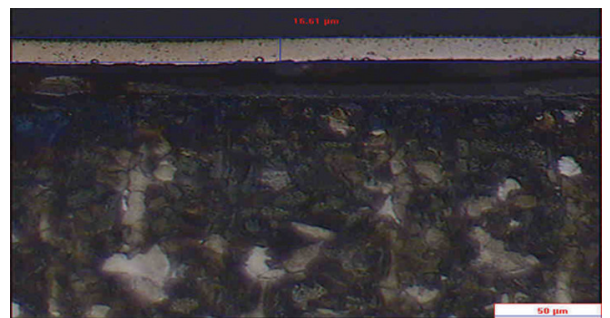

(a)

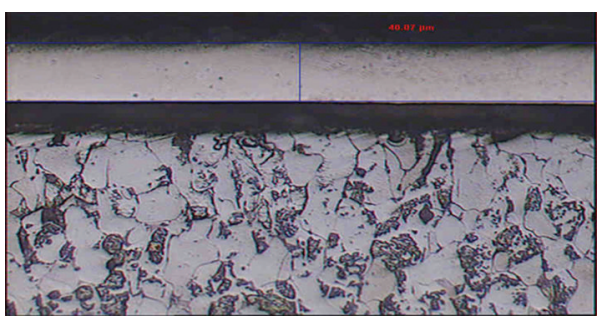

(c)

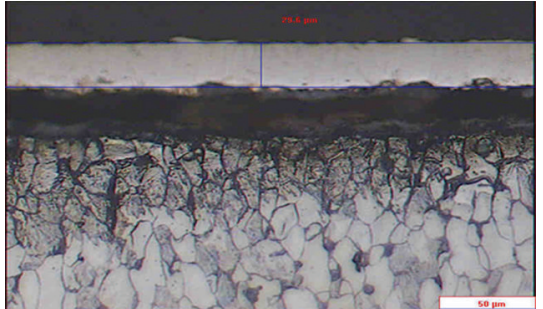

(b)

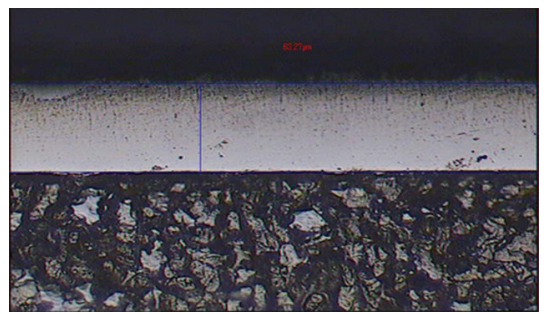

(d)

Figure 3: Micrograph of Ni-Co plated on mild steel surface at $60^{\circ} \mathrm{C}$ for (a) $0.1 \mathrm{~A} / \mathrm{cm}^{2}$, (b) $0.3 \mathrm{~A} / \mathrm{cm}^{2}$, (c) $0.5 \mathrm{~A} / \mathrm{cm}^{2}$, and (d) $1 \mathrm{~A} / \mathrm{cm}^{2} \mathrm{current}$ densities.

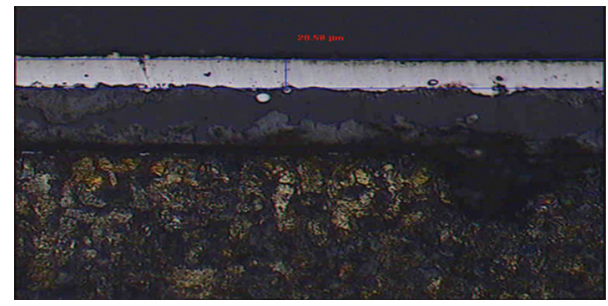

(a)

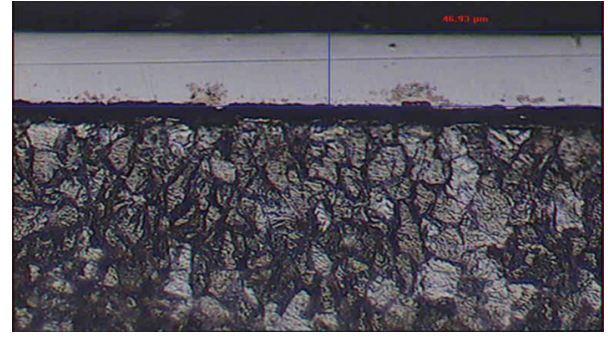

(c)

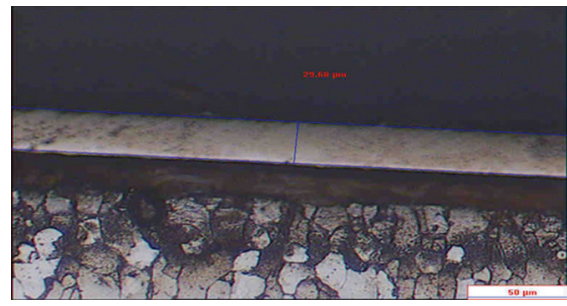

(b)

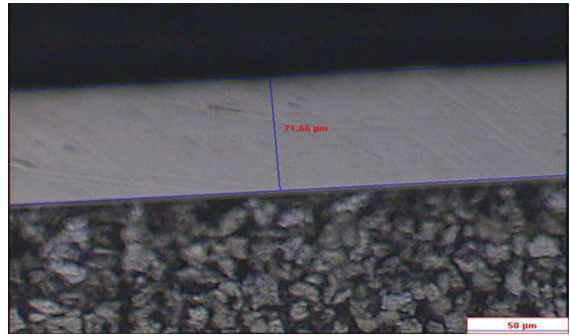

(d)

Figure 4: Micrograph of Ni-Co plated on mild steel surface at $65^{\circ} \mathrm{C}$ for (a) $0.1 \mathrm{~A} / \mathrm{cm}^{2}$, (b) $0.3 \mathrm{~A} / \mathrm{cm}^{2}$, (c) $0.5 \mathrm{~A} / \mathrm{cm}^{2}$, and (d) $1 \mathrm{~A} / \mathrm{cm}^{2} \mathrm{current}$ densities. 


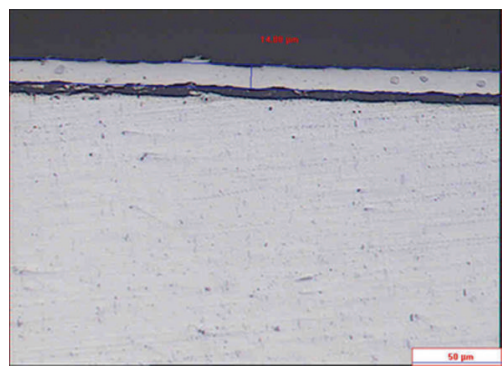

(a)

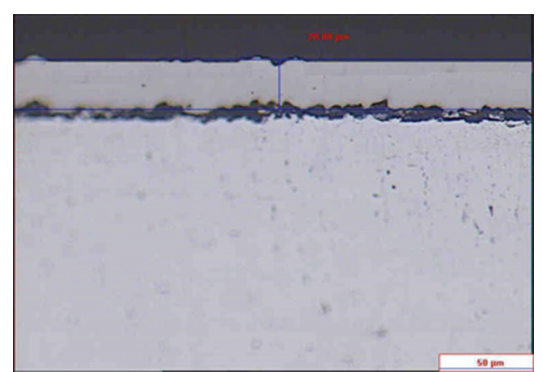

(b)

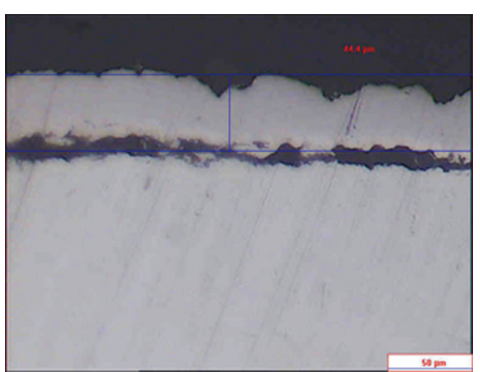

(c)

Figure 5: Micrograph of Ni-Co plated on aluminum surface at $55^{\circ} \mathrm{C}$ for (a) $0.1 \mathrm{~A} / \mathrm{cm}^{2}$, (b) $0.3 \mathrm{~A} / \mathrm{cm}^{2}$, and (c) $0.5 \mathrm{~A} / \mathrm{cm}^{2}$ current densities

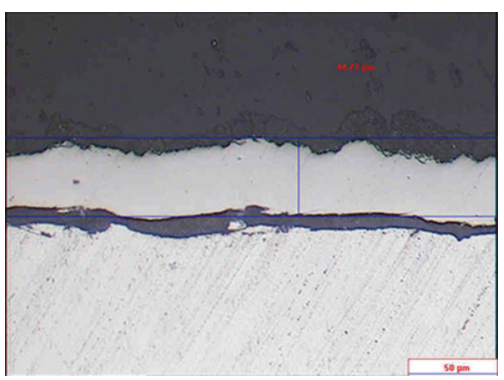

(a)

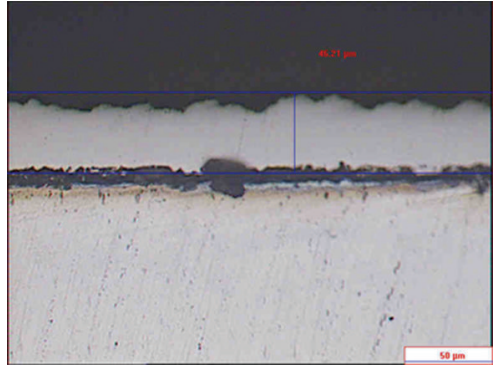

(b)

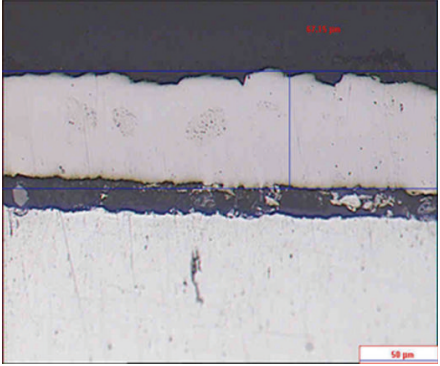

(c)

Figure 6: Micrograph of Ni-Co plated on aluminum surface at $60^{\circ} \mathrm{C}$ for (a) $0.3 \mathrm{~A} / \mathrm{cm}^{2}$, (b) $0.5 \mathrm{~A} / \mathrm{cm}^{2}$, and (c) $1 \mathrm{~A} / \mathrm{cm}^{2} \mathrm{current}$ densities.

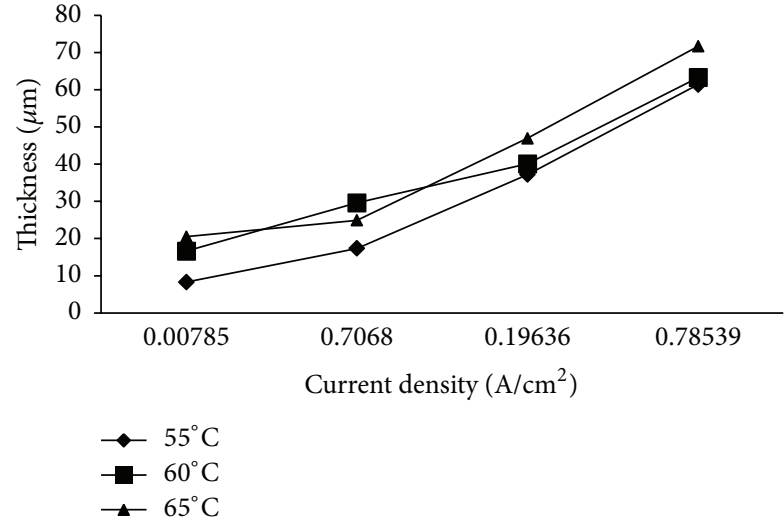

Figure 7: Effect of current density on thickness of coating.

2.3.2. Scanning Electron Microscopy. The microstructure and the chemical compositions of the phases present in the coated substrates (mild steel and aluminum) were studied using Philips XL 40 Scanning Electron Microscope equipped with an Energy Dispersive Using X-Ray (EDX) system. The polished samples were firmly held on the sample holder using a double-sided carbon tape before putting them inside the sample chamber. The SEM was operated at an accelerating voltage of 5 to $20 \mathrm{kV}$.

2.3.3. X-Ray Diffraction (XRD) Analysis. The coated substrates (mild steel and aluminum) were investigated to identify the phase constitution of the deposits alloys using X-ray diffraction (XRD) technique. It was carried out by powder diffraction method at room temperature. The D5000 Siemens

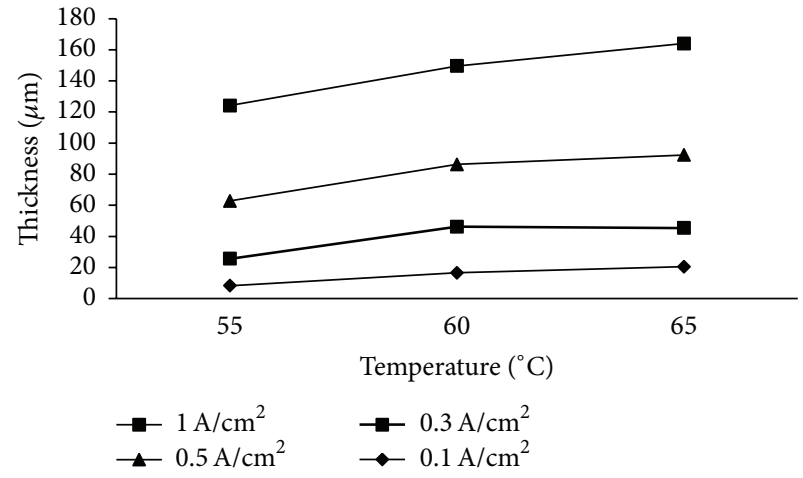

FIGURE 8: Effect of temperature on thickness of coating.

$\mathrm{X}$-ray diffractometer machine was used for the analyses. The machine uses a monochromatic $\mathrm{X}$-ray source generated from $\operatorname{CuK} \alpha(\lambda=1.5406 \AA)$ radiation. The wavelength $\lambda$ of the diffracted X-ray is plotted against the diffraction angle $2 \theta$; $n \lambda=d \sin \theta$. The diffraction pattern (peaks) was recorded accordingly.

\section{Results and Discussion}

3.1. Optical Microscopy Results. Optical microscopy was used for characterization of the microstructure of the substrates and measurement of the coating thickness to understand the effects of temperature and current density. The polished samples were used for this analysis. It was discovered that increase in the previously mentioned electroplating parameters brought about rapid increase in the coating thickness for both substrates as expected. 


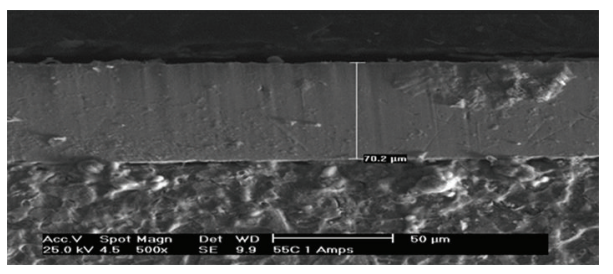

(a)

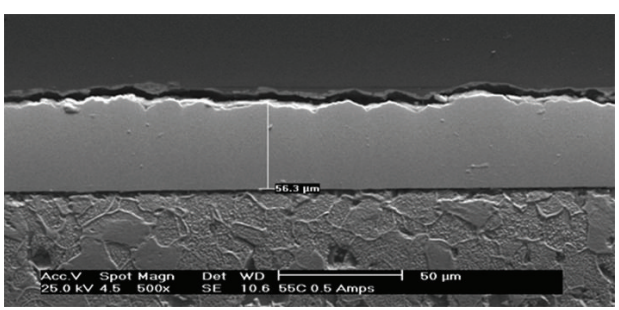

(c)

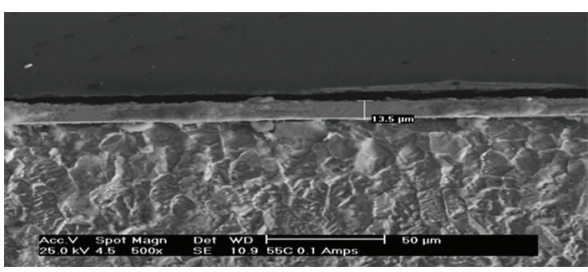

(b)

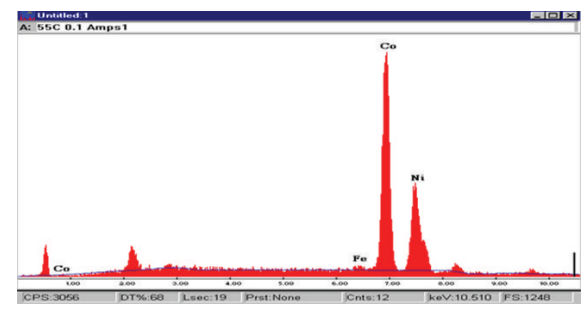

(d)

Figure 9: SEM with EDX micrograph of Ni-Co plated on mild steel surface at $55^{\circ} \mathrm{C}$ for (a) $0.1 \mathrm{~A} / \mathrm{cm}^{2}$, (b) $0.5 \mathrm{~A} / \mathrm{cm}^{2}$, and (c) $1 \mathrm{~A} / \mathrm{cm}^{2} \mathrm{current}$ densities.

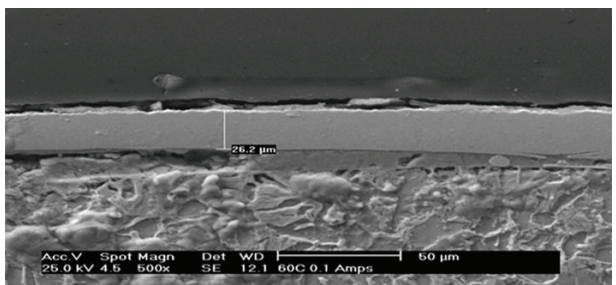

(a)

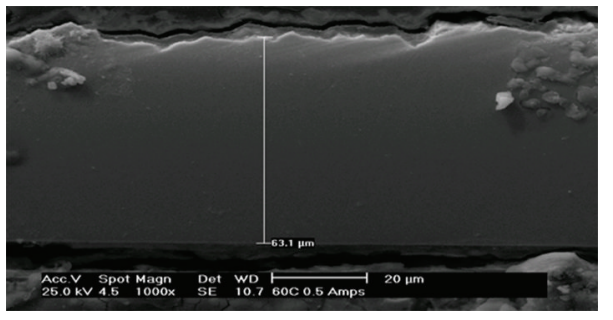

(c)

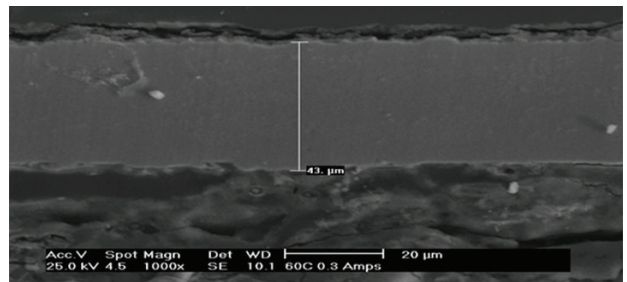

(b)

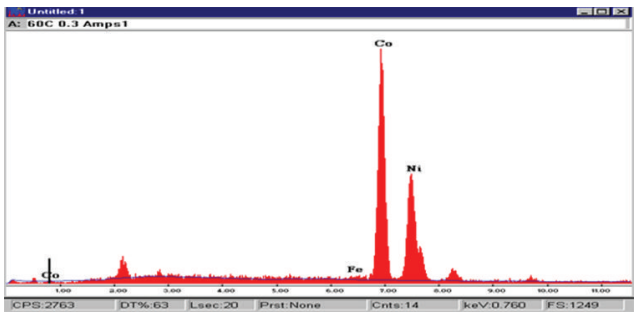

(d)

FIGURE 10: SEM micrograph of Ni-Co plated on mild steel surface at $60^{\circ} \mathrm{C}$ for (a) $0.1 \mathrm{~A} / \mathrm{cm}^{2}$, (b) $0.3 \mathrm{~A} / \mathrm{cm}^{2}$, and (c) $0.5 \mathrm{~A} / \mathrm{cm}^{2}$ current densities.

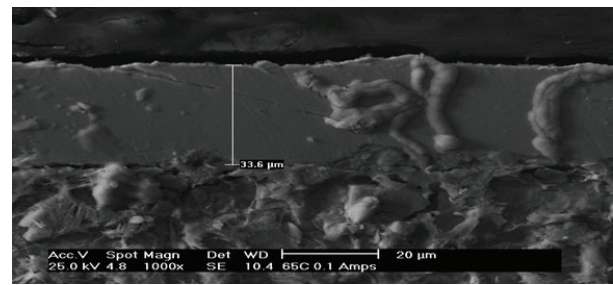

(a)

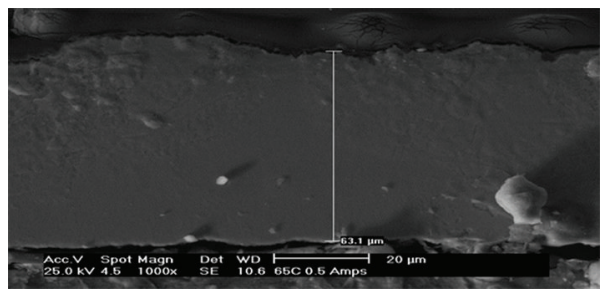

(c)

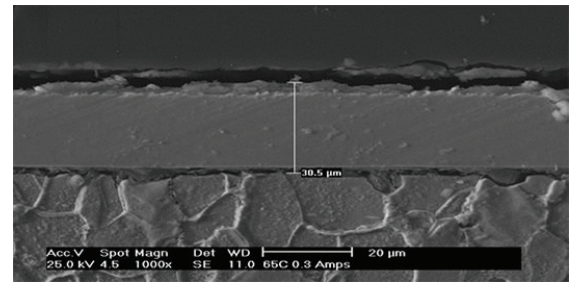

(b)

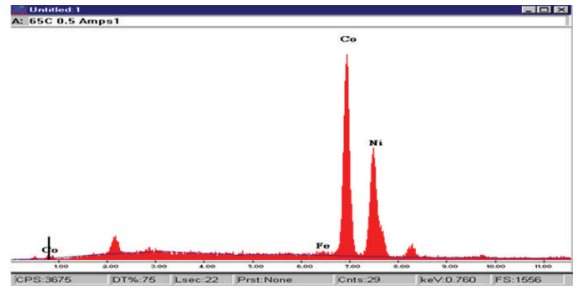

(d)

Figure 11: SEM micrograph of Ni-Co plated on mild steel surface at $65^{\circ} \mathrm{C}$ for (a) $0.1 \mathrm{~A} / \mathrm{cm}^{2}$, (b) $0.3 \mathrm{~A} / \mathrm{cm}^{2}$, and (c) $0.5 \mathrm{~A} / \mathrm{cm}^{2}$ current densities. 


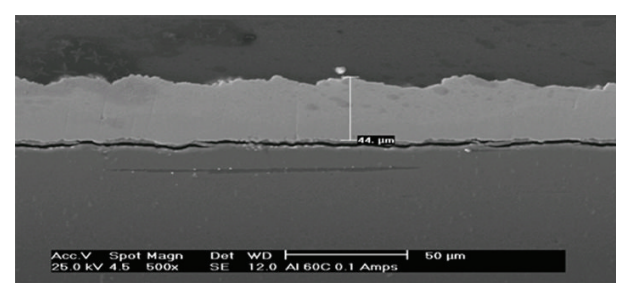

(a)

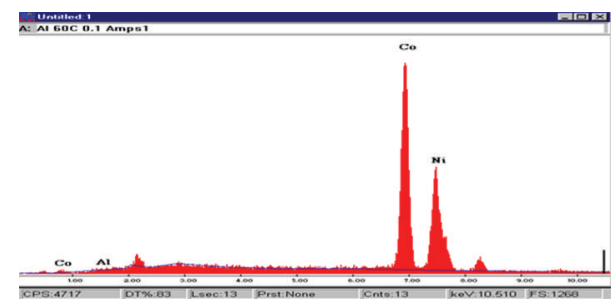

(c)

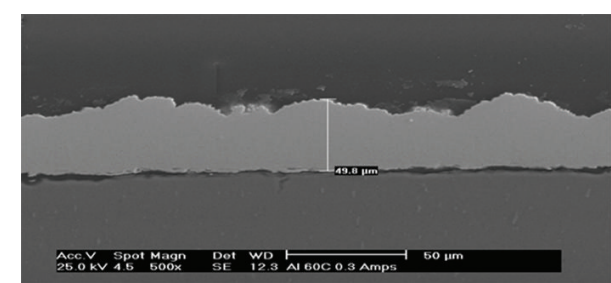

(b)

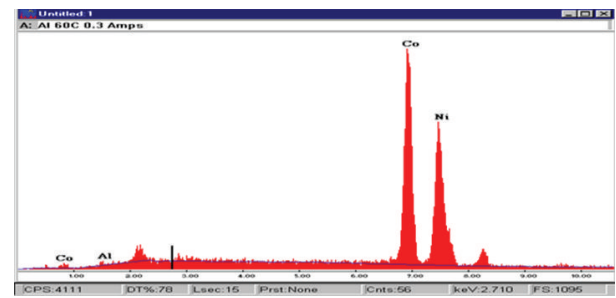

(d)

FIGURE 12: SEM micrograph Ni-Co plated on aluminum surface at $60^{\circ} \mathrm{C}$ for (a) $0.1 \mathrm{~A} / \mathrm{cm}^{2}$ and (b) $1 \mathrm{~A} / \mathrm{cm}^{2}$ current densities.

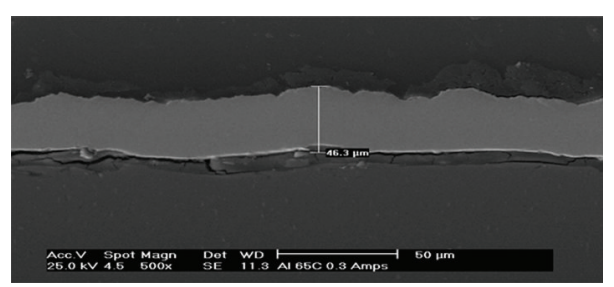

(a)

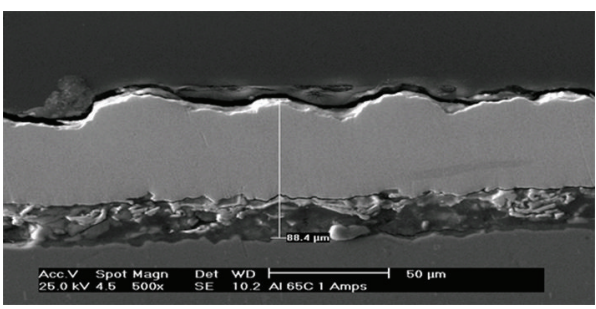

(c)

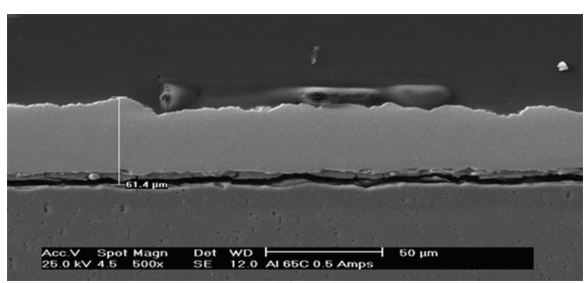

(b)

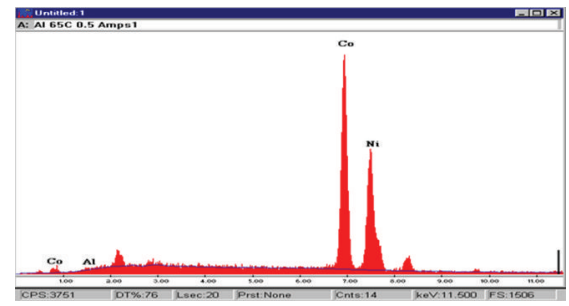

(d)

FIGURE 13: SEM micrograph of Ni-Co plated on aluminum surface at $65^{\circ} \mathrm{C}$ for (a) $0.3 \mathrm{~A} / \mathrm{cm}^{2}$, (b) $0.5 \mathrm{~A} / \mathrm{cm}^{2}$, and (c) $1 \mathrm{~A} / \mathrm{cm}^{2}$ current density.

Figure 2 reveals the micrograph image of $\mathrm{Ni}-\mathrm{Co}$ alloy samples plated at $55^{\circ} \mathrm{C}$ at various current densities. Thicknesses of $8.3 \mu \mathrm{m}, 17 \mu \mathrm{m}, 37 \mu \mathrm{m}$, and $61 \mu \mathrm{m}$ were obtained in Figures $2(\mathrm{a}-\mathrm{d})$, respectively, as shown in Figure 2. A similar result trend was obtained when the plating temperature was increased further to $60^{\circ} \mathrm{C}$ and $65^{\circ} \mathrm{C}$ as shown in Figures 3 and 4 for mild steel specimen, while Figures 5 and 6 show the microstructure of aluminum specimens. These results further confirm a practical role of current density and temperature toward the rate of deposition on the specimen [6].

3.2. Effect of Current Density. The composition, microstructure, surface morphology, and grain size of electrodeposits are dependent on current density. The current density in this process strongly influences the deposition rate, plating adherence, and plating quality. The higher the current density, the faster the deposition rate, as shown by the SEM images in Figures 9, 10, 11, 12, and 13. The increase of the cathodic current density results in increase in coating deposition rate as shown in Figure 7. At constant temperatures of $55^{\circ} \mathrm{C}, 60^{\circ} \mathrm{C}$, and $65^{\circ} \mathrm{C}$ and varying current densities, it is obvious from Figure 7 that coating thickness increases in each case. As the current is increased, the thickness of coating increases rapidly [10]. However, current density has no significant effect on the chemical composition of the deposited layer. In addition, from the chart at higher current density of $0.7854 \mathrm{~A} / \mathrm{cm}^{2}$, increasing temperature does improve thickness of the coating.

3.3. Effect of Temperature. Temperature is one of the anchor parameters in synthesis of metal and alloys by electrodeposition, as it affects deposition rate, knowing that most reactions involved in the deposition process are endothermic. 


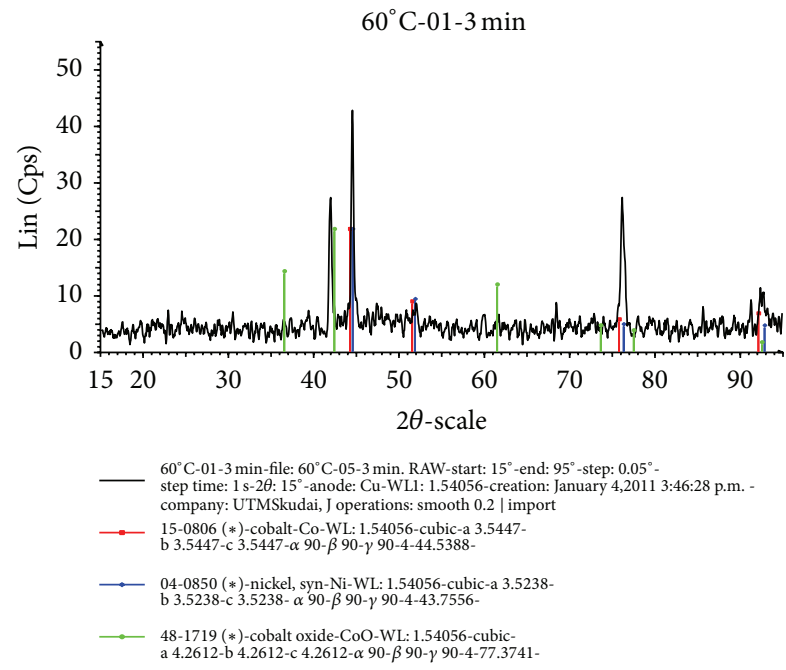

FIGURE 14: XRD analysis of Ni-Co plated on mild steel surface at $60^{\circ} \mathrm{C}$ temperature and $0.3 \mathrm{~A} / \mathrm{cm}^{2}$.

Hence, by increasing the temperature of the bath, the rate of deposition increases as stated in previous study by Qiao et al. [7]. During synthesis of Ni-Co alloys by high speed jet electrodeposition, the plot shown in Figure 3 reveals that coating thickness increases as temperature increases for current densities $1 \mathrm{~A} / \mathrm{cm}^{2}, 0.5 \mathrm{~A} / \mathrm{cm}^{2}, 0.3 \mathrm{~A} / \mathrm{cm}^{2}$, and $0.1 \mathrm{~A} / \mathrm{cm}^{2}$. However, there is no further significant increase in thickness at $65^{\circ} \mathrm{C}$. The coating thickness increased from $61.4 \mu \mathrm{m}$ to $71.7 \mu \mathrm{m}$ at temperatures $55^{\circ} \mathrm{C}$ and $65^{\circ} \mathrm{C}$, respectively, for current density $1 \mathrm{~A} / \mathrm{cm}^{2}$. Similarly, thickness also increased as the temperature increases from $55^{\circ} \mathrm{C}$ to $65^{\circ} \mathrm{C}$ for current densities $0.5 \mathrm{~A} / \mathrm{cm}^{2}, 0.3 \mathrm{~A} / \mathrm{cm}^{2}$, and $0.1 \mathrm{~A} / \mathrm{cm}^{2}$ from $37.2 \mu \mathrm{m}$ to $46 \mu \mathrm{m}$, $17.3 \mu \mathrm{m}$ to $24.9 \mu \mathrm{m}$, and $8.3 \mu \mathrm{m}$ to $20.5 \mu \mathrm{m}$, respectively. Increase in temperature results in grain growth due to free growth mode of nickel [11] which consequently leads to increase in the coating thickness (Figure 8).

3.4. Composition and Microstructure of Ni-Co Alloy Deposits. The morphology and the chemical compositions of the phases present in the coated substrates (mild steel and aluminum) were characterized by using Scanning Electron Microscope equipped with an Energy Dispersive Using X-Ray (EDX) system. As expected, there was an increase in the coating thickness for both substrates and the presence of Ni-Co phase. Figure 9 shows SEM image of Ni-Co alloy sample plated at different temperatures and current densities. The sample in Figure 9(a) shows a plated thickness of approximately $13.5 \mu \mathrm{m}$, and as current density was increased from 0.1 to $0.5 \mathrm{~A} / \mathrm{cm}^{2}$, the thickness of Ni-Co alloy deposit increases as shown in Figure 9(b). The thickness increased further when the current density was increased to $1 \mathrm{~A} / \mathrm{cm}^{2}$ to be approximately $70.2 \mu \mathrm{m}$ as given in Figure 9(c).

The results revealed that the increase in current density will yield upward increase in the thickness of the coated Ni-Co alloy. Similarly, increase in temperature produced the same related result for aluminum as shown in Figures 12(a)12 (c) and $13(\mathrm{a})-13(\mathrm{c})$ at temperatures of $60^{\circ} \mathrm{C}$ and $65^{\circ} \mathrm{C}$, respectively; increase in thickness of $\mathrm{Ni}$-Co was also visible as

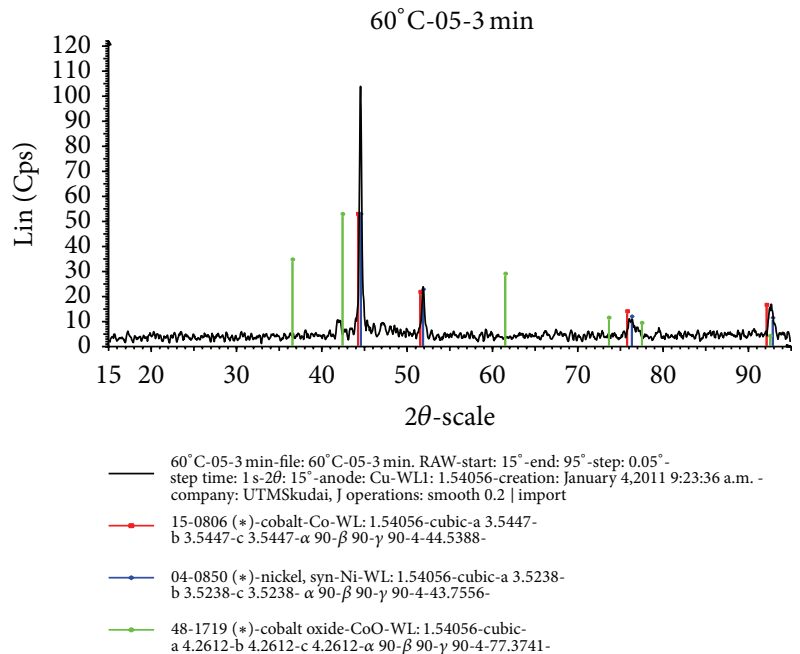

FIGURE 15: XRD analysis of Ni-Co plated on mild steel surface at $60^{\circ} \mathrm{C}$ temperature and $0.5 \mathrm{~A} / \mathrm{cm}^{2}$.

the temperature was raised. The presence of $\mathrm{Ni} / \mathrm{Co}$ is clearly shown in the EDX images of all the plated samples.

3.5. X-Ray Diffractometry Results. The coatings on the substrates (mild steel and aluminum) were analyzed to identify the phase constitution of the deposits using X-ray diffraction (XRD). The XRD analysis result shows the presence of nickel, cobalt, and cobalt oxide on all the plated samples as shown in Figures 14 and 15. It is also evident that the peak at lower current density is broader which shows more grain refinement at low current density. On the other hand, grain size increases as current density increases, and this is confirmed from the narrowness of the peak as current density increases. However, determining grain size from alloy compounds from data obtained from XRD is complex [12]. At low current density, grain growth is inhibited due to hydrogen adsorption [11].

\section{Conclusions}

Nanocrystalline Ni-Co alloy synthesis by high speed electrodeposition has been studied using high speed electrodeposition method. The following conclusions can be drawn from the obtained experimental data and results. Direct electroplating of Ni-Co over mild steel and aluminium was realized by high speed electrodeposition without preplating. NanoNi-Co particle was achieved by high speed electrodeposition, and the thickness of Ni-Co layer increased with increasing temperature and current density.

\section{Acknowledgments}

The authors express their appreciation to the lecturers and lab technicians in the Department of Materials Engineering, Faculty of Mechanical Engineering, Universiti Teknologi Malaysia, for their moral and technical support. This work was partially supported by the Ministry of Higher Education of Malaysia (MOHE), Research Management Centre, Universiti Teknologi Malaysia, through GUP Grant no. $04 \mathrm{H} 73$. 


\section{References}

[1] A. Sanaty-Zadeh, K. Raeissi, and A. Saidi, "Properties of nanocrystalline iron-nickel alloys fabricated by galvano-static electrodeposition," Journal of Alloys and Compounds, vol. 485, no. 1-2, pp. 402-407, 2009.

[2] G. Qiao, T. Jing, N. Wang et al., "Effect of current density on microstructure and properties of bulk nanocrystalline Ni-Co alloys prepared by JED," Journal of the Electrochemical Society, vol. 153, no. 5, pp. C305-C308, 2006.

[3] P. Yong, J. Shan, D. Ying, T. Tian, Z. Zhao-Feng, and Z. Yi-Chun, "Preparation and characterization of jet-electrodeposited nanocrystalline nickel coatings," Transactions of Nonferrous Metals Society of China, vol. 17, pp. 770-775, 2007.

[4] D. Golodnitsky, Y. Rosenberg, and A. Ulus, "The role of anion additives in the electrodeposition of nickel-cobalt alloys from sulfamate electrolyte," Electrochimica Acta, vol. 47, no. 17, pp. 2707-2714, 2002.

[5] G. Qiao, T. Jing, N. Wang et al., "High-speed jet electrodeposition and microstructure of nanocrystalline Ni-Co alloys," Electrochimica Acta, vol. 51, no. 1, pp. 85-92, 2005.

[6] R. Oriňáková, A. Oriňák, G. Vering, I. Talian, R. M. Smith, and H. F. Arlinghaus, "Influence of $\mathrm{pH}$ on the electrolytic deposition of Ni-Co films," Thin Solid Films, vol. 516, no. 10, pp. 3045-3050, 2008.

[7] G. Qiao, T. Jing, N. Wang et al., "High-speed jet electrodeposition and microstructure of nanocrystalline Ni-Co alloys," Electrochimica Acta, vol. 51, no. 1, pp. 85-92, 2005.

[8] L. C. Burzynska, "The influnce of elctrolysis parameters on the composition and morphology of Co-Ni alloys," Hydrometallurgy, vol. 54, pp. 133-149, 2000.

[9] R. Oriňáková, A. Turoňová, D. Kladeková, M. Gálová, and R. M. Smith, "Recent developments in the electrodeposition of nickel and some nickel-based alloys," Journal of Applied Electrochemistry, vol. 36, no. 9, pp. 957-972, 2006.

[10] A. Brenner, Electrodeposition of Alloys Principles and Practice, vol. 2, Academic Press, New York, NY, USA, 1963.

[11] T. Fritz, W. Mokwa, and U. Schnakenberg, "Material characterisation of electroplated nickel structures for microsystem technology," Electrochimica Acta, vol. 47, no. 1, pp. 55-60, 2001.

[12] V. Ganesh, D. Vijayaraghavan, and V. Lakshminarayanan, "Fine grain growth of nickel electrodeposit: effect of applied magnetic field during deposition," Applied Surface Science, vol. 240, no. 14, pp. 286-295, 2005. 

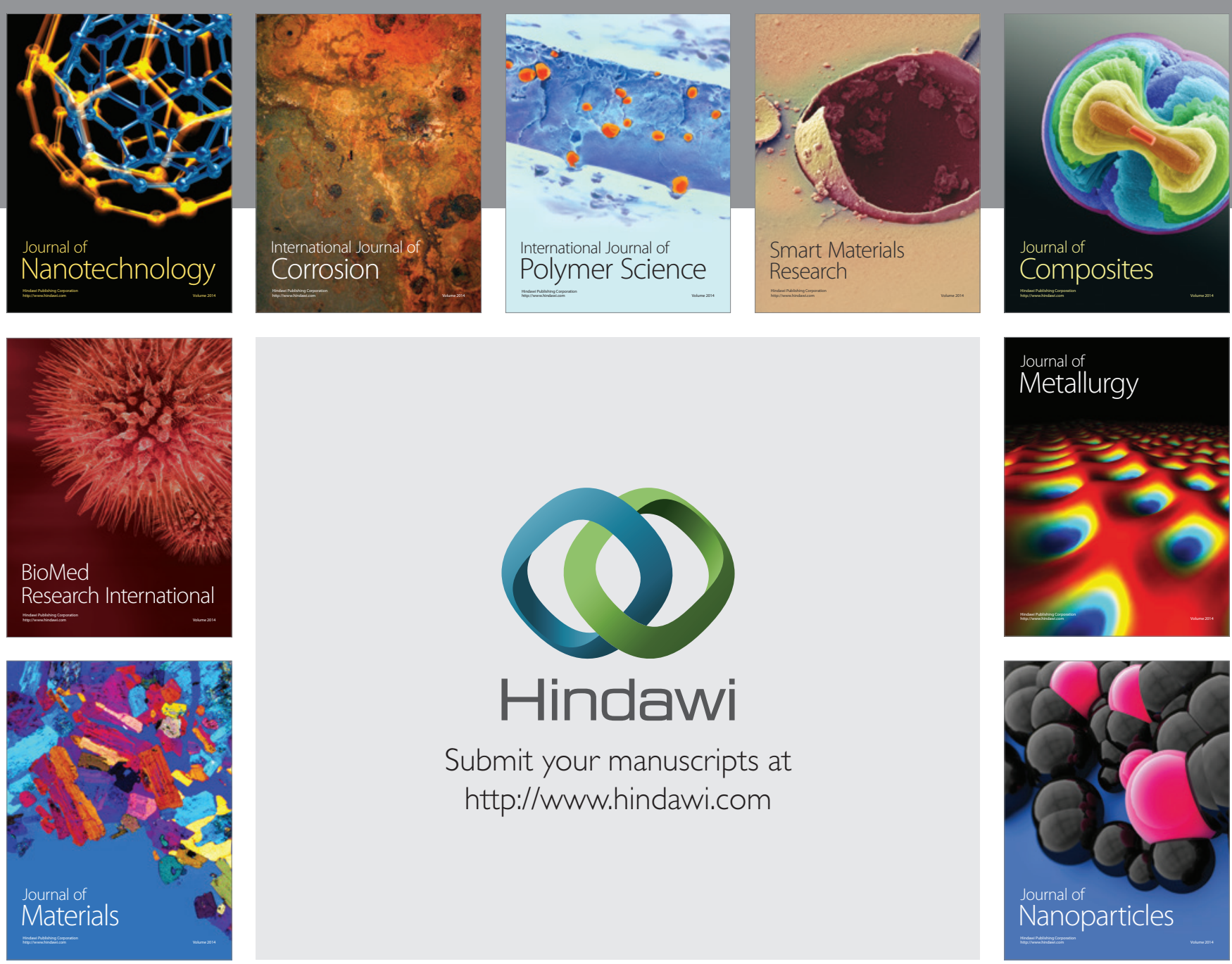

Submit your manuscripts at http://www.hindawi.com
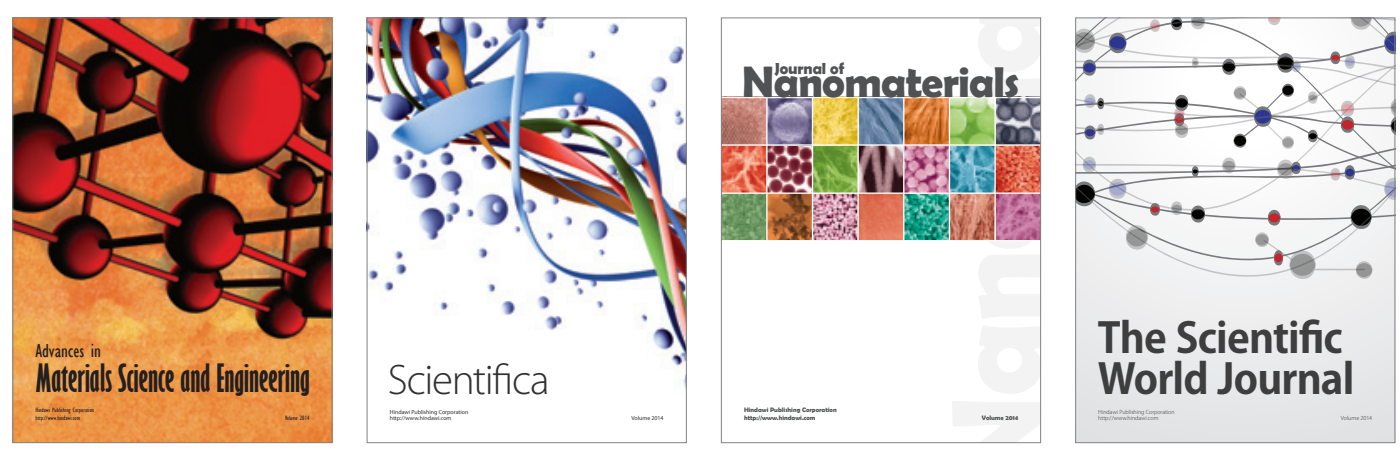

\section{The Scientific World Journal}
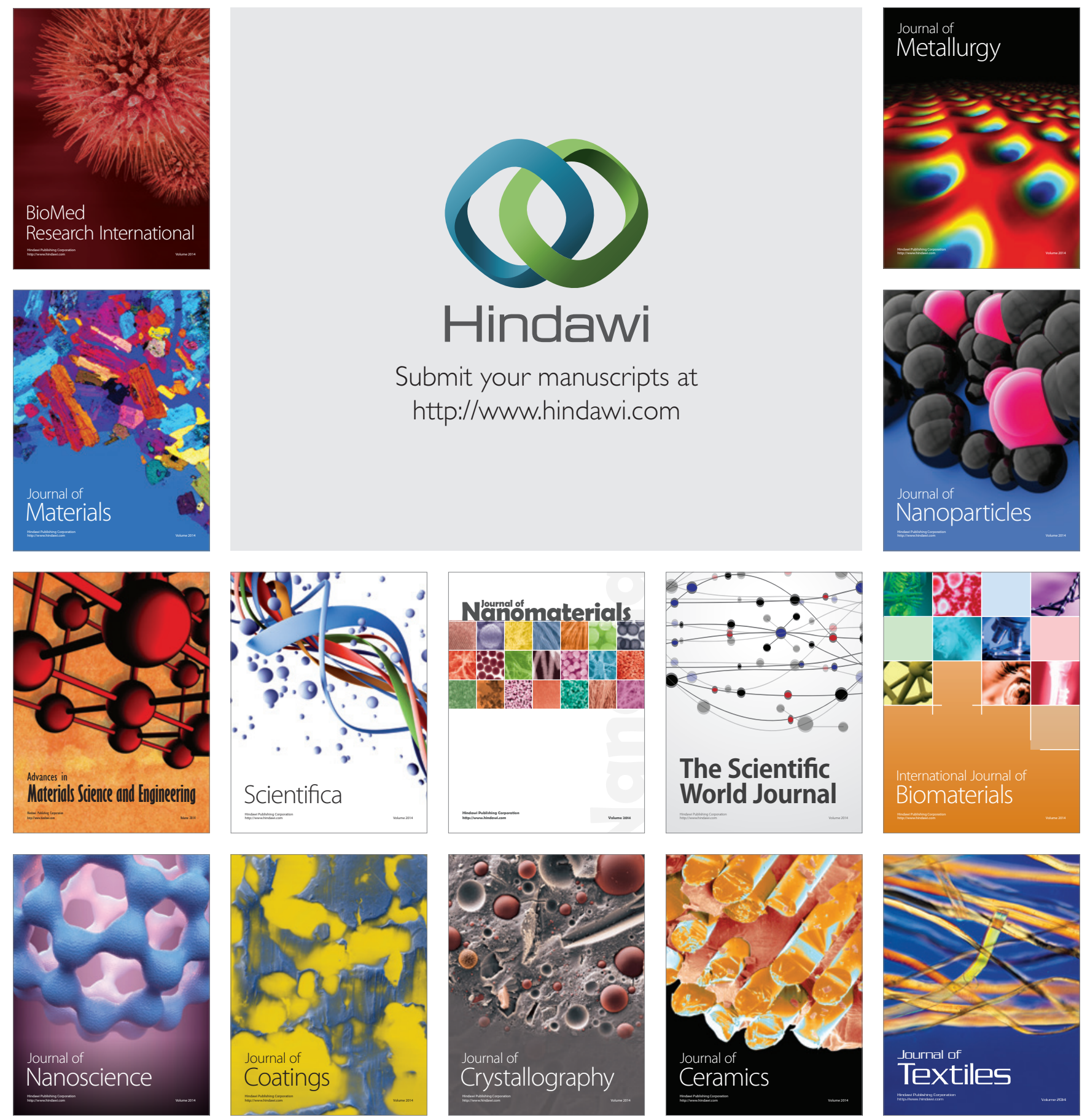